\title{
Chinese test takers' attitudes towards the Versant English Test: a mixed-methods approach
}

Jinsong Fan

\author{
Correspondence: \\ jinsongfan@fudan.edu.cn \\ Language Testing Center, College \\ of Foreign Languages and \\ Literatures, Fudan University, No. \\ 220, Handan Road, Yangpu District, \\ Shanghai 200433, People's Republic \\ of China
}

\begin{abstract}
This study investigated Chinese test takers' attitudes towards the Versant English Test (VET), an automated spoken English test developed by Pearson Knowledge Technologies. Based on previous attitudinal studies, 'attitude' in this study was conceptualized as a hypothetical psychological construct which consisted of three components: beliefs, opinions, and emotions. In data collection and analysis, this study adopted the mixed-methods sequential explanatory design. Quantitative data were collected through a questionnaire while qualitative data were collected through follow-up semi-structured interviews and focus-group discussions. The findings of this study indicate that test takers had overall positive attitudes towards the VET, believing that the VET largely reflected their spoken English ability. Test takers' gender and background had no significant relationship with their reported attitude. Despite the satisfactory face validity of the VET, this study also found that test takers still preferred the more traditional speaking tests (e.g., the IELTS-style live interviews) because these tests were believed to be more authentic and tap into a wider range of English speaking competencies. The findings of this study have implications for the VET provider in light of the further improvement and promotion of the test. Meanwhile, the findings are also meaningful to other providers of spoken English tests of a similar nature.
\end{abstract}

Keywords: Test taker's attitude; Test validity; Versant English Test

\section{Background}

Attitude, defined as 'a psychological tendency that is expressed by evaluating a particular entity with some degree of favor or disfavor' (Eagly \& Chaiken, 1993, p. 1), has been extensively researched in social psychology. In the field of second language acquisition, numerous studies have demonstrated that a learner's positive attitudes towards the target language or the target-language culture have a beneficial impact on their language learning (e.g., Brown, 2000; Ellis, 1999). Gardner (1985), for example, believes that attitude and other affective variables are as important as aptitude for language achievement. Despite the widely recognized importance of attitude in second language learning, there is no evidence that it is adequately investigated in the field of language testing (Murray et al. 2012).

Two reasons might explain the paucity of attitudinal research in language testing. First, test taker's attitude towards a language test is often considered as equivalent to face validity, a concept which is defined as 'surface credibility and public acceptability

\section{Springer}

(c) 2014 Fan; licensee Springer. This is an Open Access article distributed under the terms of the Creative Commons Attribution License (http://creativecommons.org/licenses/by/4.0), which permits unrestricted use, distribution, and reproduction in any medium, provided the original work is properly credited. 
of a test' (Ingram, 1977, p. 18). Since face validity is based on subjective evaluation of laypeople and not a statistical model, it is frequently dismissed as unscientific and irrelevant by testing researchers (e.g., Bachman, 1990; Stevenson, 1985). Secondly, 'attitude' itself is an elusive hypothetical construct which cannot be directly measured (e.g., Eagly \& Chaiken, 1993). To date, several terms have been used to describe a test taker's attitude towards a language test including, for example, 'reactions' (Elder et al. 2002), 'feedback' (Brown, 1993), 'views' (Wu, 2008), and 'psychological factors' (Jin \& Cheng, 2013). Similarly, this construct has been interpreted and operationalized in manifold ways in previous studies (e.g., Fan \& Ji, 2014; Murray, et al., 2012; Rasti, 2009; Zhao \& Cheng, 2010).

The first reason, i.e. attitude is synonymous to face validity, is not tenable because attitude as a hypothetical construct has a wider scope which often subsumes face validity. Furthermore, in response to the argument that face validity is unscientific and irrelevant, some convincing counter-arguments have been presented by researchers. For example, Alderson et al. (1995, p. 173) argue that face validity is important because if test takers consider a test to be face valid, 'they are more likely to perform to the best of their ability on that test and to respond appropriately to items'. According to Karelitz (2013, p. 2), face validity is important because it can affect examinees' motivation to prepare for and perform well on a language test, and the willingness of potential examinees to take the test. Drawing upon the recent developments in test validation theory (e.g., Kane, 2006), Karelitz cogently presents how to integrate evidence about face validity into building an interpretative validity argument. In addition to these counterarguments about the importance of examining face validity, some empirical studies have demonstrated that how test takers perceive a test is related to how they prepare for the test and respond to the test items (e.g., Elder, et al., 2002; Fan \& Ji, 2014; Zhao \& Cheng, 2010), hinting that attitude is related, directly or indirectly, to construct validity. Murray et al. (2012) argue that a test taker's attitude towards a language test forms part of test impact, which is one of the essential qualities in Bachman and Palmer's (1996) test usefulness framework and described by Shohamy (1998) as consequential validity. Messick (1989) also explicitly recommends that attitude be considered as a crucial source of evidence for construct validity.

In relation to the second reason, i.e. 'attitude' is a hypothetical construct which is difficult to operationalize and measure, we believe it is important to apply the general theoretical frameworks of this construct in social psychology to the needs of a particular research situation (see also Fan \& Ji, 2014). In the domain of social psychology, attitude is generally believed to be a construct consisting of three inter-related components: affective, cognitive, and conative (e.g., Eagly \& Chaiken, 1993), and this tripartite division of attitude has been widely accepted in language studies (e.g., Baker, 1992; Ladegaard, 2000). Based on this definition, Murray et al. (2012, p. 7) argue that a test taker's attitude towards a language test should be a unitary construct consisting of three components: beliefs (that a proposition is or is not true), opinions (that an actual or hypothetical action should or should not happen), and emotions (corresponding to 'affective' in the tripartite division of attitude). Given the purpose of this study which is to investigate test takers' attitudes towards the Versant English Test (VET), a spoken English test developed by Pearson Knowledge Technologies (Pearson, 2008), we decided to adopt the tripartite division of attitude (e.g., Baker, 1992) as a broad point of reference and Murray et al.'s (2012) 
interpretations of this construct. The conceptualization of attitude in this study is presented schematically in Figure 1.

\section{The Versant English Test}

The VET is a fully automated spoken English test developed by Pearson. According to the test description and validation summary published by Pearson (2008, p. 1), the VET is intended to evaluate the facility in spoken English of people whose native language is not English. 'Facility' is defined as 'the ability to understand the spoken language on everyday topics and to speak appropriately in response at native-like conversational pace in an intelligible form of the language' (Bernstein et al. 2010, p. 358). The VET can be delivered over the telephone or on a computer. As a fully automated spoken English test, the VET system can analyze test takers' responses and report their test scores within minutes of the completion of the test. Test administrators and score users can view and print out test scores from a password-protected website (Pearson, 2008).

The VET consists of six parts: Reading, Repeat, Short Answer Questions, Sentence Builds, Story Retelling, and Open Questions. The test format of the VET is presented in Table 1 together with a brief description of each task in the VET and the number of items in each part. The test results that test takers receive include a numeric composite score and four diagnostic subscores in Sentence Mastery, Vocabulary, Fluency, and Pronunciation (Pearson, 2008). According to Bernstein et al. (2010, p. 360), of the four diagnostic scores, Sentence Mastery and Vocabulary measure the linguistic content of the response, and Fluency and Pronunciation measure the manner in which the response is said. Accurate content indicates how well the test taker understands the prompt and responds with appropriate linguistic content while the manner scores indicate how close the test taker's articulation, rhythm, phrasing, and pausing are to the majority of native speakers, as determined by statistical models based on a large sample of native speaker data. Of the 63 items in the VET, 57 responses are currently used in the automatic scoring, excluding the two items in Open Questions and each first item in Reading, Repeat, Short Answer Questions, and Sentence Builds (Pearson, 2008). For

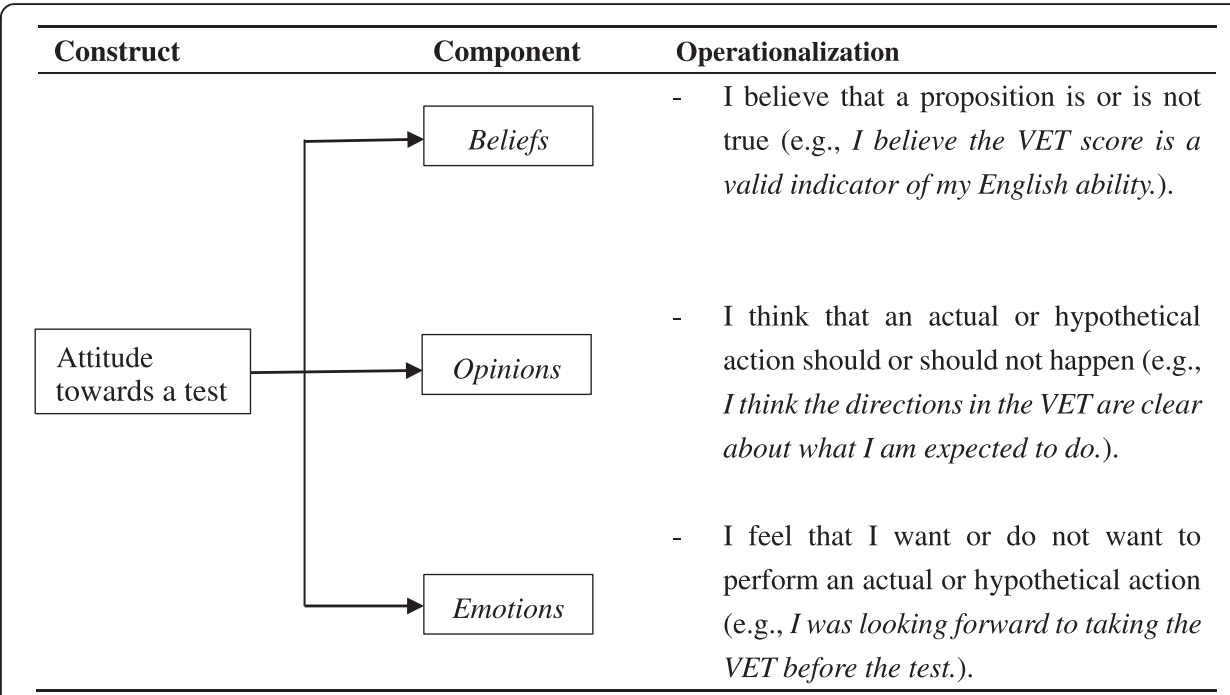

Figure 1 The conceptualization of attitude in this study (adapted from Murray et al., 2012). 
Table 1 Test format and content of the VET

\begin{tabular}{lll}
\hline Item type & Task description & Number of items \\
\hline 1) Reading & $\begin{array}{l}\text { Test takers read printed, numbered sentences, } \\
\text { one at a time, in the requested order. }\end{array}$ & 8 \\
2) Repeat & Test takers repeat sentences verbatim. & 16 \\
3) Short answer questions & $\begin{array}{l}\text { Test takers listen to spoken questions in English } \\
\text { and answer each question with a single word } \\
\text { or short phase. }\end{array}$ & 24 \\
& $\begin{array}{l}\text { Test takers rearrange three short phrases presented } \\
\text { in a random order into a sentence. }\end{array}$ & 10 \\
5) Sentence builds & $\begin{array}{l}\text { Test takers listen to a story and describe what } \\
\text { happened in their own words. }\end{array}$ & 3 \\
6) Open questions & $\begin{array}{l}\text { Test takers present their views or opinions after } \\
\text { listening to a question in English. }\end{array}$ & 2 \\
\hline
\end{tabular}

a detailed explanation of the theories underpinning the VET scoring algorithm, readers are referred to Bernstein et al. (2010).

Several types of validity evidence have been collected to support the VET score interpretations and use, including, for example, construct representation and concurrent validity evidence (Bernstein, et al., 2010). The construct measured in the VET, as explained earlier, is the facility in spoken language which is operationalized in the VET through the six item types (see Table 1). Though the VET does not simulate conversations in real-life communicative situations (which is the perceived advantage of the IELTS-style Oral Proficiency Interview, known as OPI, see Farhady, 2008), the VET scores, which reflect test takers' facility in spoken language, seem to be able to predict their performance in generally effective speech communication. In addition to construct representation, concurrent validation data has lent strong support to the validity of the VET. For example, in two studies comparing human rating and machine rating, correlation coefficients were reported at 0.81-0.86 $(\mathrm{n}=151$, Present-Thomas \& Van Moere, 2009) and $0.77(\mathrm{n}=130$, Farhady, 2008), indicating high levels of agreement in test takers' performance on the VET and human tests. Thus, as Bernstein et al. (2010, p. 374) concluded, the facility scoring implements an empirically derived quantitative model of listening and speaking performance at different levels of L2 proficiency, and the psychometric data suggest that facility is an important component of effective speech communication or oral proficiency.

A review of the existing studies of the VET reveals that the vast majority of them have been concentrated on justifying the theoretical rationale for linking test taker ability to test scores (construct definition of facility in spoken language performance) and psychometric data, in particular in relation to the concurrent evidence (e.g., correlations between the scores yielded by the VET and the other English language tests). However, test takers, as the most important stakeholders in any assessment situation, are either unaware of, or uninterested in the theoretical reasoning or psychometric properties of a test (Karelitz, 2013). Though as we argued earlier, the investigation of test takers' attitude should constitute an important component in construct validation (e.g., Alderson, et al., 1995; Messick, 1989), no systematic study has ever been reported as to how test takers view this fully automated English speaking test. This study is therefore intended to fill in this research gap through investigating Chinese test takers' attitudes towards the VET. 


\section{The present study}

The main objective of this study is to investigate Chinese test takers' attitudes to the VET, adopting the conceptualization of 'attitude' as schematized in Figure 1. Though some studies have been reported of test takers' attitude towards language tests (e.g., Fan \& Ji, 2014; Jin \& Cheng, 2013; Murray, et al., 2012; Rasti, 2009; Zhao \& Cheng, 2010), none of them was focused on a computer-based English speaking test, not to mention a fully automated one. The anecdotal evidence we have collected through interacting with Chinese students and teachers seems to suggest that many of them do not like fully automated speaking tests; neither do they place sufficient trust in the validity of such tests. The investigations of test takers' attitudes to the VET can therefore help us clarify whether such anecdotal evidence holds true.

Secondly, test takers' attitude has been regarded as part of test impact (Murray, et al., 2012; Zhao \& Cheng, 2010). A fair test, according to Kunnan (2000; see also AERA, APA, \& NCME, 1999), should function equally among different groups of test takers in terms of both psychometric properties and impact. It is therefore essential to investigate whether demographic and/or experiential variables affect test takers' reported attitude. In the present study, the two most relevant demographic and experiential variables are gender and background.

Finally, as suggested by Murray et al. (2012), while investigating test takers' attitude, it is essential to pinpoint the sources of the positivity and negativity in their reported attitude. A clear understanding of the sources of attitude can help the test provider and validators paint a fine-grained picture about test takers' attitude, thus paving the way for more informed decisions in future test improvement and test score interpretations.

Contextualized within the existing research literature, this present study seeks to address the following three research questions:

RQ1. What is the overall pattern of test takers' attitude towards the VET?

$R Q 2$. What is the relationship between test takers' gender and background and their reported attitude to the VET?

$R Q 3$. What are the sources of the positivity and negativity in test takers' reported attitude to the VET?

\section{Method}

Participants

A total of 118 students from a research university in east China participated in the questionnaire survey. For all participants in this study, Chinese is their first language. Of the 118 students, 72 (61\%) were female and 46 (39\%) were male. These students came from different academic backgrounds with 54 (45.8\%) of them majoring in the domain of humanities and $64(54.2 \%)$ in science. At the time of investigation, all of them were studying for their Bachelor's degree at this university. After the questionnaire survey, 12 students also participated in the follow-up semi-structured interviews on a voluntary basis, and another six students participated in two focus-group discussions with three students in each group.

\section{Instruments}

Two instruments were adopted for this study: a questionnaire and an interview guide. The questionnaire was designed on the basis of the conceptualization of 'attitude' as 
schematized in Figure 1. The initial draft of the questionnaire was intended to be as comprehensive as possible, containing a total of 30 items, all on a six point Likert scale of agreement (with ' 1 ' standing for 'completely disagree' and '6' standing for 'completely agree'). The six point scale was adopted with a view to avoiding central tendency effect when respondents answered the questionnaire items (Dornyei \& Taguchi, 2011). In line with the conceptualization of 'attitude' in this study (see Figure 1), the 30 items were generally divided into three components: beliefs, opinions, and emotions. At the end of the questionnaire, participants were required to provide their personal information, including gender and academic background.

After the questionnaire was drafted, it underwent several revisions. First, it was sent to five experienced researchers in the field of language testing for comment. As a result, seven items were deleted because they were believed to be either irrelevant or confusing to the prospective respondents. Then the revised questionnaire was piloted among a group of 52 students from the same university where the experiment was to be conducted. Based on the feedback from these students and some initial data analyses (e.g., exploratory factor analysis), another three items were deleted, leaving a total of 20 items in the final version of the questionnaire. Cronbach's $\alpha$ for the pilot study data was $0.80(\mathrm{n}=20)$, indicating satisfactory internal consistency.

The interview guide, designed on the basis of the questionnaire, consisted of six open-ended questions, including, for example, asking respondents to briefly describe their test-taking experience, comment on the design, validity, and delivery of the VET, and their primary motivation in taking the VET. The six questions in the interview guide were also used to scaffold the focus-group discussions.

\section{Data collection procedures}

The participants in this study were recruited through emails. Two months before the experiment, the researcher sent emails to 300 students, calling for participation in this study. Thanks to the generous support from Pearson Knowledge Technologies, the provider of the VET, all participants in this study were exempt from the charges of taking the VET. In response to the call for participation, 161 students volunteered to participate in this study. The rather low response rate is understandable since currently the VET is not widely known to Chinese university students. Upon receiving the confirmation of participation, we sent the VET information pack to students, including an introduction to the VET and practice test papers. Students were also encouraged to visit the official website of the VET to obtain further information about the test.

The VET was administered to the participants in April, 2014 at two language laboratories. Efforts were made to ensure that the testing procedures conformed to the good testing practice as prescribed by the VET provider (Pearson, 2008). Due to the bad weather on the examination day, only 118 participants took the test and completed the survey questionnaire. Before taking the VET, each participant signed the consent form. The questionnaire was administered to the participants immediately after they had completed the VET. The interview and focus-group data were collected in the two weeks following the examination. All interviews and focus-group discussions were conducted on an anonymous basis, which were recorded, and then transcribed verbatim for analysis. 


\section{Data analysis}

This study adopted the mixed-methods sequential explanatory design which consisted of two consecutive phases, first quantitative, then qualitative, in data collection and analysis. According to Ivankova et al. (2006, p.9), priority is typically given to the quantitative approach in the sequential explanatory design 'because the quantitative data collection comes first in the sequence and often represents the major aspect of the mixedmethod data collection process'. The smaller qualitative component follows in the second phase of the research. The sequential explanatory design that this study adopted is presented schematically in Figure 2.

In the quantitative phase of this study, the following statistical analyses were performed on the collected data:

a) Exploratory factor analysis (EFA) was performed on the 20 items to investigate the construct structure of the questionnaire, and internal consistency reliability coefficients Cronbach's $\alpha$ were computed at both the factor and scale level. In addition, Pearson's product moment correlations were computed to investigate the relationships between the factors extracted by the EFA.

b) To address $R Q 1$, descriptive statistics at the factor and item level were computed. In addition, frequency statistics of each item were computed. To do this, the categories of 'strongly agree', 'agree', and 'somewhat agree' were merged into one overall 'agree' category, as were the categories of 'strongly disagree', 'disagree', and 'somewhat disagree' into a single 'disagree' category. Then a non-parametric Chi-square difference test was run on the observed frequencies to determine whether the differences in participants' responses were statistically different. On some occasions, paired-samples t-tests were performed to investigate whether the mean differences in participants' responses were statistically significant.

c) To address $R Q 2$, we first of all added all the items in the questionnaire to represent test takers' overall attitude to the VET. Then, based on the median of overall attitude, we divided the cohort into 'more positively' and 'more negatively' oriented

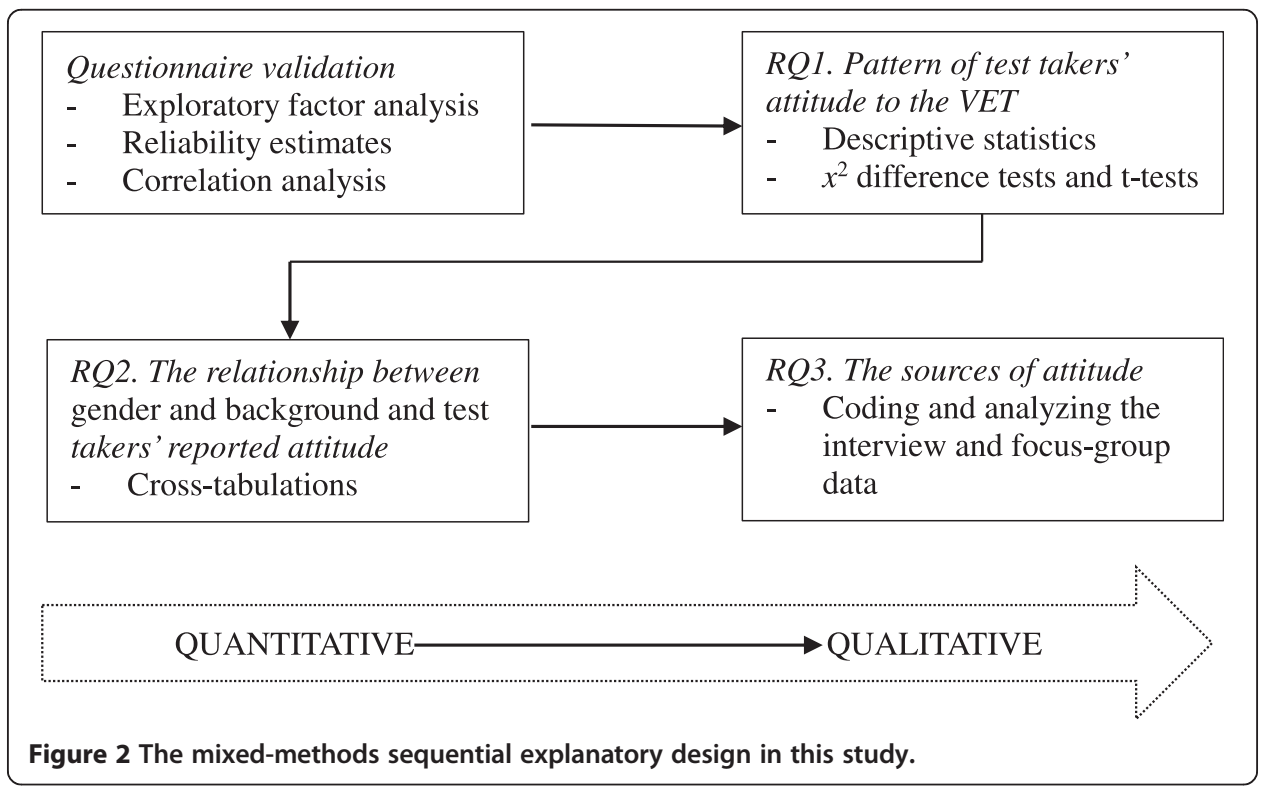


groups. Finally, cross-tabulations were run to find out whether test takers' gender and background had any significant effect on the tendency of their reported attitude to the VET.

The qualitative component, according to Figure 2, followed the quantitative phase of this study. To address $R Q 3$, the qualitative data collected through individual interviews and focus-group discussions were coded and analyzed, adopting an inductive approach (Given, 2008). To do this, a coding scheme was developed for this study after the researcher conducted several preliminary readings to identify the salient and recurring themes in the data. Then based on the coding scheme, two researchers coded the transcriptions of the interview and focus-group data independently. Inter-coder agreement was confirmed by calculating both Cohen's kappa statistic $(k=0.81)$ and the percentage of agreement between the two coders (93.17\%). Quantitative analyses in this study were performed in IBM SPSS 21.0 (IBM, 2012), and the level of all tests of significance was set at 0.05 . The qualitative data in this study were analyzed with the aid of NVivo 8.0 (Richards, 2005).

\section{Results}

Exploratory factory analysis and reliability estimates

Principal axis factoring with oblimin rotation was performed on the 20 items in the questionnaire. Oblimin rotation was adopted to enhance the interpretability of factor solutions because this questionnaire was basically measuring one overall construct, i.e. test takers' attitude to the VET and its dimensions should be correlated. Prior to EFA, skewness and kurtosis of all items in the questionnaire were checked, demonstrating that the data satisfied the criterion of univariate normality. The Kaiser-Meyer-Olkin measure (0.79) and Bartlett's test of sphericity $(p<0.001)$ were examined, both suggesting the suitability of the data for factor analysis. The Kaiser Criterion was adopted which meant only factors with eigenvalues over one would be extracted (Field, 2009). Results of EFA indicated that five factors had eigenvalues over Kaiser's criterion of one, which in combination explained $56.78 \%$ of the variance. No items were deleted from this analysis since each of them had factor loadings over 0.4 and none of them had double loadings over 0.4 on two different factors (Stevens, 2002).

Based on item loadings on the five factors, Factor 1 was interpreted as 'test takers' perceived validity of the VET' (hereafter 'face validity', Item 1, 2, 3, 4, 8, Cronbach's $\alpha=0.87$ ), Factor 2 was interpreted as 'extrinsic motivation in taking the VET' (hereafter 'extrinsic motivation', Item 12, 13, 14, Cronbach's $\alpha=0.88$ ), Factor 3 was interpreted as 'test takers' perceived interestingness of the tasks in the VET' (hereafter 'interestingness', Item 15, 16, 17, 18, 19, 20, Cronbach's $\alpha=0.86$ ), Factor 4 was interpreted as 'test takers' views on the VET delivery' (hereafter 'test delivery', Item 5, 6, 7, Cronbach's $\alpha=0.70$ ), and Factor 5 was interpreted as 'intrinsic motivation in taking the VET' (hereafter 'intrinsic motivation', Item 9, 10, 11, Cronbach's $\alpha=0.63$ ). Cronbach's $\alpha$ for the whole questionnaire was 0.88. The results of EFA are summarized in Table 2 together with Pearson's correlations between the five attitudinal factors. As can be seen from Table 2, the questionnaire was a reliable instrument (factor-level $\alpha$ from 0.63 to 0.87 ) which measured different dimensions of test takers' attitude towards the VET. Results of inter-factor correlations demonstrate that except the correlations between extrinsic 
Table 2 Summary of EFA results and inter-factor correlations

\begin{tabular}{llllllll}
\hline Factor & No of item & $\mathbf{a}$ & $\mathbf{F 1}$ & $\mathbf{F 2}$ & $\mathbf{F 3}$ & $\mathbf{F 4}$ & F5 \\
\hline 1. Face validity & $1,2,3,4,8$ & 0.87 & 1 & 0.13 & $0.50^{* *}$ & $0.39^{* *}$ & $0.30^{* *}$ \\
2. Extrinsic motivation & $12,13,14$ & 0.88 & & 1 & $0.26^{* *}$ & 0.16 & $0.26^{* *}$ \\
3. Interestingness & $15,16,17,18,19,20$ & 0.86 & & & 1 & $0.35^{* *}$ & $0.32^{* *}$ \\
4. Test delivery & $5,6,7$ & 0.70 & & & & 1 & $0.27^{* *}$ \\
5. Intrinsic motivation & $9,10,11$ & 0.63 & & & & & 1 \\
\hline
\end{tabular}

Notes. ${ }^{* *}$ correlations are significant at $p<0.01$ level. F1: face validity; F2: extrinsic motivation; F3: interestingness; F4: test delivery; F5: intrinsic motivation.

motivation (F2) and face validity (F1) and test delivery (F4), all other correlations are significant at the $p<0.01$ level, suggesting that the five attitudinal factors are closely related. The low correlations between extrinsic motivation and other two attitudinal factors (i.e. face validity and test delivery) can probably be explained by the fact that all participants of this study were voluntary.

\section{The pattern of test takers' attitude to the VET (RQ1)}

To investigate the pattern of test takers' attitude towards the VET, descriptive statistics at the factor level were first of all computed. This was done by adding all the items in the factor, and then divided the item total by the number of items. The results demonstrated that of the five attitudinal factors, test takers had the most positive attitude to the delivery of the VET, and their views were quite uniform, as was suggested by the small standard deviation $(\mathrm{M}=4.82, \mathrm{SD}=0.80)$. In addition, test takers' intrinsic motivation in taking the VET seemed much stronger than their extrinsic motivation (intrinsic: $\mathrm{M}=4.26, \mathrm{SD}=0.82$; extrinsic: $\mathrm{M}=3.44, \mathrm{SD}=1.08$ ), and the difference was shown to be statistically significant by a paired-samples $t$-test $(\mathrm{t}=7.62, d f=117, p<0.05, d=$ 0.89 ). The mean values of the other two factors were comparable (face validity: $M=$ $4.14, \mathrm{SD}=0.81$; interestingness: $\mathrm{M}=4.08, \mathrm{SD}=1.03$ ), both suggesting a moderate tendency towards positivity.

To investigate test takers' attitude to the VET in more detail, descriptive statistics of each item in the questionnaire were computed. In addition, frequencies and percentages of participants' responses to each individual item were calculated. A nonparametric test of Chi-square was run on the observed frequencies in order to find out if the differences in participants' responses were statistically significant. The results of item-level statistics are presented in Table 3. As can be seen from this table, the mean magnitudes of most items are greater than 3.5 , suggesting an overall tendency towards positivity. This is particularly noticeable in the items that are related to test delivery (Item $5,6,7$ ) with only a small percentage of respondents expressing disagreement with the statement in each item (from $5.9 \%$ to $11.9 \%$, see frequency statistics in Table 3). In addition, the overwhelming majority of the respondents (93.2\%) agreed that they took the VET with a view to assessing their spoken English ability, lending support to the finding derived from factor-level statistics. Given the fact that all participants in this study were voluntary, the finding came as no surprise to us.

According to Table 3, the lowest mean values mostly clustered in the factor of extrinsic motivation. For example, only $42.4 \%$ of the respondents agreed that they took the VET because the VET certificate could be used for applying to study overseas. Again, the finding came as not surprising because the VET is currently not widely known to 
Table 3 Descriptive and frequency statistics at the item-level

\begin{tabular}{|c|c|c|c|c|}
\hline Item & Mean & SD & $\begin{array}{l}\text { Disagree frequency } \\
\text { (Percentage) }\end{array}$ & $\begin{array}{l}\text { Agree frequency } \\
\text { (Percentage) }\end{array}$ \\
\hline 1. The design of the VET was reasonable. & 4.14 & 0.95 & $21(17.8 \%)$ & $97(82.2 \%)$ \\
\hline $\begin{array}{l}\text { 2. I believe the VET well reflected my } \\
\text { spoken English ability. }\end{array}$ & 4.09 & 0.95 & $26(22.0 \%)$ & $92(78.0 \%)$ \\
\hline $\begin{array}{l}\text { 3. The abilities measured in the VET were } \\
\text { essential to oral communications. }\end{array}$ & 4.36 & 0.96 & $16(13.6 \%)$ & $102(86.4 \%)$ \\
\hline $\begin{array}{l}\text { 4. The content of the VET reflected what } \\
\text { I needed in real life language use. }\end{array}$ & 4.52 & 1.04 & $12(10.2 \%)$ & $106(89.8 \%)$ \\
\hline 5. The length of the VET was appropriate. & 4.76 & 0.83 & $9(7.6 \%)$ & $109(92.4 \%)$ \\
\hline $\begin{array}{l}\text { 6. The demo before the test helped me } \\
\text { perform to the best of my abilities. }\end{array}$ & 4.99 & 0.97 & $7(5.9 \%)$ & $111(94.1 \%)$ \\
\hline 7. The directions were clear. & 4.72 & 1.22 & $14(11.9 \%)$ & $104(88.1 \%)$ \\
\hline $\begin{array}{l}\text { 8. I had adequate opportunities to prove } \\
\text { my oral English in the VET*. }\end{array}$ & 3.60 & 1.09 & $51(43.2 \%)$ & $67(56.8 \%)$ \\
\hline 9. I looked forward to taking the VET. & 4.05 & 1.15 & $35(29.7 \%)$ & $83(70.3 \%)$ \\
\hline 10. I took the VET to assess my English. & 4.84 & 0.98 & $8(6.8 \%)$ & $110(93.2 \%)$ \\
\hline $\begin{array}{l}\text { 11. I took the VET because I really enjoyed } \\
\text { learning English. }\end{array}$ & 3.90 & 1.10 & $40(33.9 \%)$ & $78(66.1 \%)$ \\
\hline $\begin{array}{l}\text { 12. I took the VET because its score was } \\
\text { widely recognized by authorities. }\end{array}$ & 3.55 & 1.14 & $57(48.3 \%)$ & $61(51.7 \%)$ \\
\hline $\begin{array}{l}\text { 13. I took the VET because its certificate } \\
\text { was useful when applying for overseas study*. }\end{array}$ & 3.47 & 1.22 & $61(51.7 \%)$ & $57(48.3 \%)$ \\
\hline $\begin{array}{l}\text { 14. I took the VET because its certificate could } \\
\text { help me when seeking employment. }\end{array}$ & 3.31 & 1.23 & $68(57.6 \%)$ & $50(42.4 \%)$ \\
\hline 15. I felt 'Reading' task was interesting. & 3.80 & 1.34 & $43(36.4 \%)$ & $75(63.6 \%)$ \\
\hline 16. I felt 'Repeat' was interesting. & 3.72 & 1.23 & $47(39.8 \%)$ & $71(60.2 \%)$ \\
\hline 17. I felt 'Questions' was interesting. & 4.21 & 1.29 & $32(27.1 \%)$ & $86(72.9 \%)$ \\
\hline 18. I felt 'Sentence Builds' was interesting. & 4.19 & 1.44 & $30(25.4 \%)$ & $88(74.6 \%)$ \\
\hline 19. I had fun working on 'Story Retelling'. & 4.36 & 1.40 & $24(20.3 \%)$ & $94(79.7 \%)$ \\
\hline 20. I enjoyed working on 'Open Questions'. & 4.19 & 1.31 & $31(26.3 \%)$ & $87(73.7 \%)$ \\
\hline
\end{tabular}

Notes. The items in this table were translated from the Chinese version, and are somewhat different from what they appeared in the questionnaire; ${ }^{*}$ Chi-square test not significant.

Chinese university students. Of the six tasks in the VET, participants commented most positively on 'Story Retelling' (Item $19, \mathrm{M}=4.36, \mathrm{SD}=1.40$ ) and least positively on 'Reading' (Item 15, M = 3.8, SD =1.34) and 'Sentence Builds' (Item 16, M=3.72, $\mathrm{SD}=1.23)$. To further investigate whether participants' attitude to the six tasks was significantly different, we merged participants' responses to the first four tasks, i.e. Reading, Repeat, Short Answer Questions, and Sentence Builds, because all of them adopted the selected-response format (see Table 1). The same procedure was then applied to test takers' responses to the other two constructed-response tasks, i.e. Story Retelling and Open Questions. Paired-samples $t$-test was then run to compare participants' responses. The result showed that participants' responses to the constructedresponse tasks were significantly more positive than the selected-response tasks $(\mathrm{t}=3.1$, $d f=117, p<0.05, d=0.29)$.

Furthermore, the results of non-parametric Chi-square tests demonstrated that the differences of participants' responses were statistically significant on 16 out of the 20 items $(p<0.05)$ with more participants choosing 'agreement' over 'disagreement'. Of 
the four items on which participants' responses were statistically not significant $(p>0.05)$, three were in the factor of extrinsic motivation (Item 12, 13. 14) while the other one in the factor of face validity (Item 8 , see Table 3 ). These results suggest that there was an overall tendency towards positivity in test takers' reported attitude. However, their views seemed divergent when it came to extrinsic motivation and the opportunities to demonstrate their English proficiency in the VET.

\section{Gender, background, and test takers' attitude (RQ2)}

To investigate whether test takers' gender and academic background had any significant effect on their reported attitude, cross-tabulations on these two variables and test takers' overall attitude to the VET were performed. This investigation is worthwhile because, as we argued earlier, test takers' attitude is believed to be part of test impact, and a fair test should function equally among different groups of test takers.

To run cross-tabulations, we first added all the items in the questionnaire to form test takers' overall attitude to the VET. Then the cohort was divided into two groups based on the median of the overall attitude score (83): 'more positively oriented group' (those whose scores were over 83) and 'more negatively oriented group' (those whose scores were below 83). Cross-tabulations were then performed to find out whether gender and background were predictors of the tendency to fall into one or the other attitude group. Results of the cross-tabulations are presented in Table 4. As can be seen in Table 4, the two variables of test takers' demographic and experiential variables, i.e. gender and background, did not predict any significant difference among the participants in terms of their overall attitude to the VET ( $p>0.05$ in both cases).

The sources of test takers' attitude to the VET (RQ3)

To more accurately pinpoint the sources of test takers' attitude to the VET, the qualitative data were coded and analyzed with the aid of NVivo. The qualitative data in this study, as explained earlier, consisted of 12 individual interviews and two focus group discussions with three participants in each group. After the data were coded, we first of all computed the frequencies of participants' responses at each category in the coding scheme, and the results are presented in Table 5. As can be seen from Table 5, participants' responses were most frequently concentrated on the design of the VET and least frequently on future improvement of the VET and their test-taking motivation. In the category of the test design, participants commented most frequently on the face validity of the VET.

Table 4 Results of cross-tabulations

\begin{tabular}{|c|c|c|c|c|}
\hline & \multicolumn{2}{|c|}{ Overall attitude } & \multirow[t]{2}{*}{ Total } & \multirow{2}{*}{$\begin{array}{l}x^{2} \\
\text { Asymp. sig. (2-sided) }\end{array}$} \\
\hline & More positive & More negative & & \\
\hline Gender & & & & 0.82 \\
\hline Male & 24 & 22 & 46 & \\
\hline Female & 36 & 36 & 72 & \\
\hline Background & & & & 0.59 \\
\hline Humanities & 28 & 26 & 54 & \\
\hline Science & 30 & 34 & 64 & \\
\hline
\end{tabular}


Table 5 Frequency of participants' responses at each category

\begin{tabular}{lll}
\hline Category & Frequency & Percentage \\
\hline 1. The design of the VET & 98 & $41.7 \%$ \\
a) Face validity & 34 & $14.5 \%$ \\
b) Comparison with other tests & 18 & $7.7 \%$ \\
c) Comparison with live interviews & 17 & $7.2 \%$ \\
d) Difficulty & 16 & $6.8 \%$ \\
e) Language abilities tested & 13 & $5.5 \%$ \\
2. The six tasks in the VET & 42 & $17.9 \%$ \\
a) Selected response tasks & 24 & $10.2 \%$ \\
b) Constructed response tasks & 18 & $7.7 \%$ \\
3. Personal affect & 35 & $14.9 \%$ \\
4. Test delivery & 26 & $11.1 \%$ \\
5. Future improvement & 17 & $7.2 \%$ \\
6. Test-taking motivation & 17 & $7.2 \%$ \\
Total & 235 & $100 \%$ \\
\hline
\end{tabular}

In terms of the test design, most participants commented positively on the overall design of the VET because it has six different tasks, and the change from one task to another fills us with a sense of novelty' (Participant 3). The other reason was attributed to the progressively increasing level of difficulty for both the six tasks in the VET and the sequence of items in each part of the test. As Participant 8 pointed out, this kind of design 'could help us gradually get used to the testing situation and perform to the best of our abilities'. However, participants seemed to prefer live interview tests to automated tests because, as Participant 6 argued, 'in real life, we never talk to machines. Live interviews are definitely more interactive than a computer-based test'. This participant continued to point out that 'such a computer-based speaking test (as the VET) can well measure my pronunciation and vocabulary, but many more communicative features can be assessed in a human test, including my reasoning ability'. Despite participants' overall preference for live interview tests, most of them still believed that the VET could reflect from $70 \%$ to $90 \%$ of their spoken English ability, suggesting the satisfactory face validity of the VET. That said, a few participants expressed their lack of confidence in automated scoring that the VET adopted. A typical comment in this regard went like the following: 'I can't believe that my spoken English performance can be rated by computers. The system could probably rate my pronunciation, but how can it accurately rate my in-depth thinking and ability in argumentation?' (Participant 10) For some participants who had experience in taking other spoken English tests such as the speaking sections of TOEFL $\mathrm{iBT}$ and IELTS, they compared the VET with these tests, pointing out that the VET appeared much less challenging. They mentioned that while the speaking sections in TOEFL and IELTS could measure a wide range of spoken English abilities from fluency to reasoning and argumentation, the VET as a whole seemed to tap into the relatively superficial layer of English speaking ability including pronunciation, grammar, vocabulary, and short-term memory. These abilities, as participants said, were undoubtedly essential prerequisites to successful communication, but a mastery of these abilities did not constitute a sufficient condition to become a proficient English speaker. 
Generally speaking, the participants in interviews and focus-group discussions seemed to enjoy their experience of taking the VET with most of them describing their experience as 'positive' and 'interesting'. The qualitative data revealed that four reasons most likely explained the positivity in their experience. Firstly, the progressively increasing level of difficulty, as we reported earlier, made it easier for test takers to engage in the tasks; secondly, the overall difficulty of the VET was perceived as low, thus greatly reducing test takers' anxiety when responding to the items; thirdly, the six tasks appeared novel to test takers, or as Participant 10 described, 'I have never seen such tasks before when taking English language examinations developed in China'; fourthly, some participants mentioned that since they took the VET voluntarily they didn't have the heavy psychological burden which they often experienced when taking other high-stakes English tests.

Of the six tasks in the VET, the first four tasks, i.e. Reading, Repeat, Short Answer Questions, and Sentence Builds, were perceived to assess test takers' listening ability, speed of response, grammar, and memory while the other two tasks, i.e. Story Retelling and Open Questions, were believed to assess more integrative abilities in English speaking because 'in these two parts we are really using English flexibly to express and organize our ideas' (Participant 2 in Focus Group 2). The first four parts, therefore, were intended to 'pave the way for the other two tasks' (Participant 10). Most participants commented that compared with the first four parts, the other two tasks better reflected their English ability, and they couldn't reason why the last part, i.e. Open Questions, was not included in the scoring procedures. Consistent with the findings derived from quantitative analyses, most participants commented positively on the delivery of the VET, believing that the length was appropriate and the directions were very clear. A few participants, however, mentioned that some information should be made more transparent to test takers such as the language abilities that each task was intended to assess and the rationales underpinning the scoring procedures. As expected, the VET was not well known to participants, many of whom said that they came to know about this test 'only after reading the information pack and visiting the official website of the VET' (Participant 9). Though some participants acknowledged that they took the VET because, according to the VET website, the test scores were recognized by many institutions all over the world and could be converted to scores on TOEFL iBT and IELTS, most of them said they took the test either with a view to assessing their spoken English ability or because they had interest in English learning and speaking.

\section{Discussion and conclusions}

The necessity of soliciting stakeholders' views in test development and validation has been widely recognized and explicitly articulated by a number of language testing researchers in recent years (e.g., AERA et al., 1999; Alderson, et al., 1995; Chun, 2008; Messick, 1989). Shohamy (2001), for example, believes that stakeholder involvement can help to democratize language testing practices and accomplish the goal of powersharing in language testing. Karelitz (2013) argues that public opinion of a test should be studied routinely throughout the life cycle of a test because negative public views 'create a unique threat to the existence of the test' (p. 4). In this study, we investigated a sample of Chinese test takers' attitudes to the VET. Taking heed of the advice from Murray et al. (2012), we not only investigated the pattern of test takers' attitudes but 
also pinpointed the sources of the positivity and negativity in their reported attitudes. Results of EFA indicate that five factors in combination represented test takers' attitude to the VET. The EFA results are consistent with the theoretical understanding of attitude in social psychology (e.g., Baker, 1992; Eagly \& Chaiken, 1993) which posits that attitude is a unitary construct consisting of multiple dimensions. In addition, the EFA results also find resonance in some previous empirical investigations of test takers' attitude towards a language test (e.g., Jin \& Cheng, 2013; Zhao \& Cheng, 2010). Given the fact that all VET test takers in this study were voluntary, it is understandable that their motivation in taking the VET was divided into two separate factors (i.e. intrinsic and extrinsic motivation, cf. Dornyei \& Schmidt, 2001), and the cohort was more intrinsically than extrinsically motivated to take the VET, as demonstrated by the paired-samples $t$-test.

Following the EFA results, descriptive and frequency statistics of the questionnaire data indicate that test takers on the whole held positive attitude to the VET, believing that the VET to a large extent reflected their spoken English proficiency. The positivity of test takers' attitude, as the qualitative data revealed, could be attributed primarily to the variety of tasks in the VET, the progressively increasing level of difficulty, test delivery, and test takers' low anxiety when taking the VET. These findings contradicted the hypothesis that we formed at the beginning of this study based on the anecdotal evidence which pointed to Chinese test takers' more negative perceptions of automated spoken English tests. Murray et al. (2012, p. 4) pointed out that 'positive attitudes towards the fairness and efficacy of a test can promote a sense of empowerment rather than helplessness, and create conditions for learning opportunities to become more effective.' Taking into account that the VET is currently not widely known to Chinese university students, these findings should be encouraging to the VET provider. Test takers' negative attitude, on the other hand, was mainly concentrated on the lack authenticity of the tasks in the VET, and the relatively narrow range of language abilities assessed in the VET.

Of the six tasks in the VET, test takers preferred the two tasks adopting the constructed-response format, i.e. Story Retelling and Open Questions. As a matter of fact, these two tasks are frequently used in live interview tests or non-automated computer-based tests (e.g., the speaking section of TOEFL iBT, see Farhady, 2008). This finding seems to suggest that despite test takers' overall positive attitude to the VET, they would still choose to take the more traditional speaking tests (i.e. live interview or non-automated computer-based tests) if they were given the options. One of the reasons, according to the qualitative data we collected, is the selected-response tasks are far from authentic, or as one participant in Focus Group 2 remarked, 'in real life we are never required to use language that way'. Comparatively speaking, the two constructed-response tasks appear much more authentic since test takers are required to use English flexibly to express ideas. It is not surprising, therefore, that Participant 10 described the first four tasks as 'paving the way' for the other two constructedresponse tasks. Authenticity, according to the test usefulness framework proposed by Bachman and Palmer (1996, p. 18), should be one of the essential qualities when evaluating a language test. Also, as Leung and Lewkowicz (2006, p. 213) remarked, 'the debate over the past 15 years that is more relevant to ELT pedagogy and curriculum concerns test authenticity'. For the provider of automated spoken English tests like the 
VET, how to improve the authenticity in test design without sacrificing the scientific rigor in the scoring algorithm remains a grave challenge to address in the future (see also Chun, 2006, 2008).

As perceived by the test takers in this study, the VET primarily tapped into such language abilities as listening, pronunciation, grammar, vocabulary, speed of reaction and short-term memory. These abilities are well reflected in the four diagnostic scores reported by the VET provider, i.e. Sentence Mastery, Vocabulary, Fluency, and Pronunciation. Also, these abilities largely conform to the theoretical reasoning that underpins the VET construct (e.g., Balogh \& Bernstein, 2006; Bernstein, et al., 2010; Pearson, 2008). The construct assessed in the VET, as explained earlier, is the facility in spoken language which can be further explicated as 'real-time receptive and productive processing of spoken language forms', 'the control of core language processing components, such as lexical access and syntactic encoding', and 'the ability to access and retrieve lexical items, to build phrases and clause structures, and to articulate responses without conscious attention to the linguistic code' (Pearson, 2008, pp. 8-9). To some extent, the findings of this study have lent support to the satisfactory face validity of the VET. However, it should be acknowledged that whether the VET has indeed tapped into these language abilities remains to be confirmed by future validation studies.

In addition to the above findings, we also found that demographic or experiential variables, i.e. gender and background did not predict the tendency of test takers' attitude to the VET. This finding concurs with Rasti's (2009) investigation of Iranian test takers' attitude to the IELTS but does not find resonance in Murray et al. (2012) study of test takers' attitudes towards the Professional English Assessment for Teachers (PEAT) in Australia though their conceptualization of attitude was adopted in the present study. Two reasons may explain the different findings. First, in Murray et al.'s study, the participants were language teachers, not students. These two groups of respondents might have very different perceptions of a test (e.g., Cheng, 2014). Second, the two experiential variables which significantly predicted test takers' attitude in Murray et al.'s study were teaching experience and test experience while in our study the two variables were gender and academic background. The different research results seem to suggest that depending on the testing context, some demographic or experiential variables may affect or predict test takers' attitude but the effect of other variables is negligible. Future research is necessary to further explore the role of demographic and/or experiential variables in shaping test takers' attitude.

\section{Limitations and implications}

A few limitations need to be addressed to support the accurate interpretations of research results of this study. First, the VET is a test which is not targeted specifically at university students. In fact, the VET is targeted at a wide range of potential test takers, including students, staff, and officers (Pearson, 2008, p. 3). Therefore, this study only represents how a particular group of the VET test takers view this test. Since some demographic or experiential variables, as we discussed earlier, may affect test takers' attitude, the results of this study may not be validly extrapolated to other groups of test takers such as staff in business. Secondly, the participants in this study were not VET test takers in real sense because all of them were recruited through emails and exempt 
from the test charges. Therefore, the findings of this study shall be interpreted and accepted with caution, in particular when it comes to test-taking motivation. Thirdly, though the questionnaire in this study was intended to be as comprehensible as possible, some dimensions of test takers' attitude were not included in our investigation (e.g., test anxiety, see also Zhao \& Cheng, 2010). Finally, due to practical problems, test performance data were not included in our analysis. Future research is warranted to investigate how these attitudinal factors interact with each other in shaping test takers' performance on a language test (cf. Fan \& Ji, 2014). These limitations notwithstanding, this study contributes, in a timely manner, to the understanding about test takers' feedback about this automated spoken English test, and the research results are meaningful to both the VET provider and the other VET stakeholders.

The findings of this study have implications for the VET provider and the other providers of computer-based speaking tests. First, it is necessary to use a variety of tasks to elicit test takers' spoken performance. As suggested by the current study, test takers may develop more positive attitude towards a test if it employs a variety of task formats in the assessment of English speaking. When multiple task types are employed to elicit test takers' performance, it is important for the test provider to arrange them in the sequence of progressive difficulty. Second, it is essential for speaking test providers to recognize the importance of improving the perceived interestingness of the test tasks. If test takers view the tasks as more interesting, they may also tend to view the test more positively and respond to it more actively. Finally, authenticity is an essential quality for a language test, and this is particularly true for a speaking test. Therefore, providers of computer-based speaking tests, be they automated or non-automated, should always strive to make their tests as authentic as possible because better authenticity of test tasks, as indicated by this study, is likely to induce more positive attitudes from test takers.

Competing interests

The author declares that he has no competing interests.

\begin{abstract}
Acknowledgements
The preparation of this manuscript was supported by the National Social Sciences Fund of the People's Republic of China (Grant Number: 13CYY032) and a joint research project between the Language Testing Center of Fudan University and Pearson Knowledge Technologies. An earlier draft of this article was presented as a research paper at the Pacific Rim Objective Measurement Symposium (PROMS) held in August, 2014 in Guangzhou, China. I would like to express my gratitude to Prof. Peiying Ji, Prof. Jiangbo Wan, and Ms. Diana Hon for assisting me in collecting the data for this study. In addition, thanks are due to Dr. Xiaoqiu Xu, Dr. Masanori Suzuki, and Dr. William Bonk for their very insightful comments on the previous draft of this article.
\end{abstract}

Received: 30 July 2014 Accepted: 30 September 2014

Published online: 21 October 2014

\title{
References
}

Alderson, JC, Clapham, C, \& Wall, D. (1995). Language Test Construction and Evaluation. Cambridge: Cambridge University Press.

AERA, APA, \& NCME. (1999). Standards for Educational and Psychological Testing. Washington D.C: AERA.

Bachman, LF. (1990). Fundamental Considerations in Language Testing. Oxford: Oxford University Press.

Bachman, LF, \& Palmer, AS. (1996). Language Testing in Practice. Oxford: Oxford University Press.

Baker, C. (1992). Attitudes and Language. Clevedon, UK: Multilingual Matters.

Balogh, J, \& Bernstein, J. (2006). Workable models of standard performance in English and Spanish. In Y Matsumoto, D Oshima, OR Robinson, \& P Sells (Eds.), Diversity in Language: Perspectives and Implications (pp. 20-41). Stanford: CSLI Publications.

Bernstein, J, Van Moere, A, \& Cheng, J. (2010). Validating automated speaking tests. Language Testing, 27(3), 355-377.

Brown, A. (1993). The role of test-taker feedback in the test development process: test-takers' reactions to a tape-mediated test of proficiency in spoken Japanese. Language Testing, 10, 277-303.

Brown, DH. (2000). Principles of Language Learning and Teaching (4th ed.). New York: Longman. 
Cheng, L. (2014). Consequences, impact, and washback. In AJ Kunnan (Ed.), The Companion to Language Assessment (pp. 1130-1146). New York: John Wiley \& Sons.

Chun, C. (2006). An analysis of a language test for employment: the authenticity of the PhonePass test. Language Assessment Quarterly, 3(3), 295-306.

Chun, C. (2008). Comments on 'evaluation of the usefulness of the versant for english test: a response': the author responds. Language Assessment Quarterly, 5(2), 168-172.

Dornyei, Z, \& Schmidt, R. (2001). Motivation and Second Language Acquisition. Honolulu, Hawaii: National Foreign Language Research Center.

Dornyei, Z, \& Taguchi, T. (2011). Questionnaires in Second Language Research: Construction, Administration and Processing. Beijing: Foreign Language Teaching and Research Press.

Eagly, AH, \& Chaiken, S. (1993). The Psychology of Attitudes. New York: Handcourt Brace Jovanovich.

Elder, C, Iwashita, N, \& McNamara, T. (2002). Estimating the difficulty of oral proficiency tasks: what does the test taker have to offer? Language Testing, 19(4), 347-368.

Ellis, R. (1999). Understanding Second Language Acquisition. Shanghai: Shanghai Foreign Language Education Press.

Fan, J, \& Ji, P. (2014). Test candidates' attitudes and their test performance: the case of the Fudan English Test. University of Sydney Papers in TESOL, 9, 1-35.

Farhady, H. (2008). Human operated, machine mediated, and automated tests of spoken english. Research paper presented the American Association of Applied Linguistics (AAAL) Conference. Washington, DC.

Field, A. (2009). Discovering Statistics Using SPSS (3rd ed.). London: SAGE Publications.

Gardner, R. (1985). Social Psychology and Second Language Learning: The Role of Attitude \& Motivation. London: Edward Arnold.

Given, LM. (2008). The SAGE Encyclopedia of Qualitative Research Methods (Volume 1 \& 2). London: Sage Publications Ltd. IBM. (2012). IBM SPSS Statistics 21 Core System user's Guide. New York: IMB Corp.

Ingram, E. (1977). Basic concepts in testing. In JPB Allen \& A Davies (Eds.), Edinburgh Course of Applied Linguistics (Vol. 4). Oxford: Oxford University Press.

Ivankova, N, Creswell, J, \& Stick, S. (2006). Using mixed-method sequential explanatory design: from theory to practice. Field Methods, 18(1), 3-20.

Jin, Y, \& Cheng, L. (2013). The effects of psychological factors on the validity of high-stakes tests. Modern Foreign Languages, 36(1), 62-69.

Kane, MT. (2006). Validation. In RL Brennan (Ed.), Educational Measurement (4th ed., pp. 17-64). Westport. CT: American Council on Education/Praeger.

Karelitz, TM. (2013). Using public opinion to inform the validation of test scores. Research report retrieved from www.nite.org.il/files/reports/e387.pdf.

Kunnan, AJ (Ed.). (2000). Fairness and Validation in Language Assessment. Cambridge: Cambridge University Press.

Ladegaard, HJ. (2000). Language attitudes and sociolinguistic behavior: exploring attitude-behavior relations in language. Journal of Sociolinguistics, 4(2), 214-233.

Leung, C, \& Lewkowicz, J. (2006). Expanding horizons and unresolved conundrums: language testing and assessment. TESOL Quarterly, 40(1), 211-234.

Messick, S. (1989). Validity. In RL Linn (Ed.), Educational Measurement (3rd ed., pp. 13-103). Macmillan: American Council on Education.

Murray, JC, Riazi, AM, \& Cross, JL. (2012). Test candidates' attitudes and their relationship to demographic and experiential variables: the case of overseas trained teachers in NSW, Australia. Language Testing, 29(4), 577-595.

Pearson. (2008). Versant English Test: test description and validation summary. Retrieved from www.versanttest.co.uk/ pdf/NalidationReport.pdf.

Present-Thomas, R, \& Van Moere, A. (2009). NRS classification consistency of two spoken english tests Research paper presented at the East Coast Organization of Language Testers (ECOLT) Conference. Washington DC.

Rasti, I. (2009). Iranian candidates' attitudes towards IELTS. Asia EFL Journal, 11(3), 110-155.

Richards, L. (2005). Handling Qualitative Data: A Practical Guide. London: Sage Publications.

Shohamy, E. (1998). Critical language testing and beyond. Studies in Educational Evaluations, 24(4), 331-345.

Shohamy, E. (2001). The Power of Tests: A Critical Perspective of the Uses of Lanquage Tests. London: Pearson Education.

Stevens, JP. (2002). Applied Multivariate Statistics for Social Sciences (4th ed.). Hillsdale, NJ: Erlbaum.

Stevenson, DK. (1985). Authenticity, validity, and a tea party. Language Testing, 2(1), 41-47.

Wu, J. (2008). Views of Taiwanese students and teachers on English language testing. University of Cambridge ESOL Examinations Research Note, 34(2), 6-9.

Zhao, J, \& Cheng, L. (2010). Exploring the Relationship Between Chinese University students' Attitude Towards the College English Test and Their Test Performance. In L Cheng \& A Curtis (Eds.), English Language Assessment and the Chinese Learner. New York \& London: Routledge, Taylor \& Francis Group.

doi:10.1186/s40468-014-0006-9

Cite this article as: Fan: Chinese test takers' attitudes towards the Versant English Test: a mixed-methods approach. Language Testing in Asia 2014 4:6. 